\title{
Abatement of styrene waste gas emission by biofilter and biotrickling filter: Comparison of packing
}

materials and inoculation procedures.

M.C. Pérez, F. J. Álvarez-Hornos*, K. Portune, C. Gabaldón

Research Group GI ${ }^{2} \mathrm{AM}$, Department of Chemical Engineering, Universitat de València, Av. de la Universitat s/n, 46100, Burjassot, Spain

*Corresponding author. F. Javier Álvarez-Hornos, Department of Chemical

Engineering, Universitat de València, Av. de la Universitat s/n, 46100, Burjassot, Spain.

Telephone: +34963543736 ; fax: +34963544898

E-mail: Francisco.J.Alvarez@uv.es (F. Javier Álvarez-Hornos)

URLs: http://www.uv.es/giam 


\section{Abstract}

The removal of styrene was studied using 2 biofilters packed with peat and coconut fibre (BF1-P and BF2-C, respectively) and 1 biotrickling filter (BTF) packed with plastic rings. Two inoculation procedures were applied: an enriched culture with strain Pseudomonas putida CECT 324 for biofilters and activated sludge from a municipal wastewater treatment plant for the BTF. Inlet loads (ILs) between 10 and $45 \mathrm{~g} \mathrm{~m}^{-3} \mathrm{~h}^{-1}$ and empty bed residence times (EBRTs) from 30 to $120 \mathrm{~s}$ were applied. At inlet concentrations ranging between 200 and $400 \mathrm{mg} \mathrm{Nm}^{-3}$, removal efficiencies between 70 and $95 \%$ were obtained in the 3 bioreactors. Maximum elimination capacities (ECs) of 81 and $39 \mathrm{~g} \mathrm{~m}^{-3} \mathrm{~h}^{-1}$ were obtained for the first quarter of the BF1-P and BF2-C, respectively (IL of $173 \mathrm{~g} \mathrm{~m}^{-3} \mathrm{~h}^{-1}$ and EBRT of $60 \mathrm{~s}$ in BF1-P; IL of $89 \mathrm{~g} \mathrm{~m}^{-3} \mathrm{~h}^{-1}$ and EBRT of $90 \mathrm{~s}$ in BF2-C). A maximum EC of $52 \mathrm{~g} \mathrm{~m}^{-3} \mathrm{~h}^{-1}$ was obtained for the first third of the BTF (IL of $116 \mathrm{~g} \mathrm{~m}^{-3} \mathrm{~h}^{-1}$, EBRT of $45 \mathrm{~s}$ ). Problems regarding high pressure drop appeared in the peat biofilter, whereas drying episodes occurred in the coconut fibre biofilter. DGGE revealed that the pure culture used for biofilter inoculation was not detected by day 105. Although 2 different inoculation procedures were applied, similar styrene removal at the end of the experiments was observed. The use as inoculum of activated sludge from municipal wastewater treatment plant appears a more feasible option.

Keywords: biofilter, biotrickling filter, inoculation procedures, microflora, Pseudomonas putida, styrene 


\section{Introduction}

Styrene is a volatile organic compound (VOC) classified as a hazardous air pollutant under the Clean Air Act Amendments of 1990 (USEPA 1994). It is predominantly emitted from industries producing polystyrene, styrene copolymers and polyester. The principal uses of styrene include the manufacture of plastics, latex paints and coatings, synthetic rubbers, polyesters and styrene-alkyd coatings. Styrene or its derivative products may be released into the atmosphere during any step in production, storage, transport, or utilisation. Styrene is a pollutant that contributes to tropospheric ozone formation (Derwent et al. 1996) and can affect human health (Kolstad et al. 1995). In fact, styrene has been classified as a potential carcinogen in humans by the International Agency for Research on Cancer (IARC 1987).

Recently, biotechnologies have been developed as alternatives to conventional techniques to treat waste gas with high flow rates and relatively low VOC concentrations. Biotechnologies are cost-effective due to their low operational costs, low energy requirements and an absence of residual products requiring further treatment or disposal (Kennes et al. 2009). Among the available biological gas treatments, biofilters (BFs) and biotrickling filters (BTFs) are of particular interest. These bioreactors work by passing waste air through a bed of packing material where an active biofilm is developed on its surface. The air pollutants, previously transferred from the gas phase, are mainly degraded to $\mathrm{H}_{2} \mathrm{O}$ and $\mathrm{CO}_{2}$ by the microorganisms. In $\mathrm{BFs}$, the reactor is usually filled with organic packing materials. The selection of material is one of the key factors in the successful application of BFs. Therefore, it is essential to choose the material with adequate physical and chemical properties, such as high surface area, long-term physical stability, low pressure drop, low cost, good moisture 
retention, $\mathrm{pH}$ buffering capacity, nutrients and appropriate adsorbing capacity (Shareefdeen and Singh 2005). In fact, a great variety of packing materials have been tested in BFs, such as peat, compost bark, and wood chips (Ivanpour et al. 2005; Malhautier et al. 2005). BTFs use an inert packing material and a liquid phase that trickles through the bed and provides nutrients to the biofilm. This allows for $\mathrm{pH}$ control, yielding a stable operation. The trickling liquid can be fed continuously or discontinuously into the bioreactor (Sempere et al. 2008). Because of their relatively small footprint, BTFs do not need much ground area, but do usually reach high pollutant removals (Kennes and Veiga 2013).

Several studies have proven the successful application of these biotechnologies for the removal of styrene from gas emissions, although the comparison of biofilters and biotrickling filters has not been evaluated. Arnold et al. (1997) investigated styrene removal in a peat biofilter. Inlet concentrations ranging between 50 and $1200 \mathrm{mg} \mathrm{m}^{-3}$ were applied and an average elimination capacity (EC) of $12 \mathrm{~g} \mathrm{~m}^{-3} \mathrm{~h}^{-1}$ with a maximum of $30 \mathrm{~g} \mathrm{~m}^{-3} \mathrm{~h}^{-1}$ was obtained. Dehghanzadeh et al. (2005) used a biofilter packed with yard waste compost mixed with shredded hard plastic and observed a maximum EC of $45 \mathrm{~g} \mathrm{~m}^{-3} \mathrm{~h}^{-1}$ at an inlet load (IL) of $60 \mathrm{~g} \mathrm{~m}^{-3} \mathrm{~h}^{-1}$ and an empty bed residence time (EBRT) of $120 \mathrm{~s}$. Novak et al. (2008) reported a maximum EC of $11.3 \mathrm{~g} \mathrm{C} \mathrm{m}^{-3} \mathrm{~h}^{-1}$ at an IL of 18.6 $\mathrm{g} \mathrm{C} \mathrm{m}^{-3} \mathrm{~h}^{-1}$ in a BTF packed with polypropylene Pall rings working with an EBRT of $35 \mathrm{~s}$.

Currently, more interest is aimed at opening the black box of biofiltration by unravelling the biodiversity-ecosystem function relationship (Cabrol and Malhautier 2011). In the case of the removal of styrene, the ability of the genus Pseudomonas for the degradation of this compound under aerobic conditions has been reported. Okamoto et al. (2003) tested the Pseudomonas putida strain ST201 in flask experiments, 
achieving complete styrene degradation after $48 \mathrm{~h}$ at concentrations up to $600 \mathrm{mg} \mathrm{L}^{-1}$. Jang et al. (2004) used Pseudomonas sp. SR-5 as a styrene-degrading bacterium in 2 biofilters packed with peat and a ceramic material, reporting maximum ECs of 236 and $81 \mathrm{~g} \mathrm{~m}^{-3} \mathrm{~h}^{-1}$ for the peat and ceramic BF, respectively. Paca et al. (2001) observed the predominance of Pseudomonas aeruginosa strains working at $\mathrm{pH}$ above 5 in four perlite BFs at EBRTs varying from $6.5 \mathrm{~s}$ to $26 \mathrm{~s}$ and inlet concentrations from 200 to $1000 \mathrm{mg}$ $\mathrm{m}^{-3}$

Among the inoculation procedures which were applied in the start-up of bioreactors treating styrene emissions, the use of 2 different inoculum sources has been used: enriched cultures with styrene-degrading strains (Okamoto et al. 2003; Jang et al. 2004; Kim et al. 2005) and activated sludge from wastewater treatment plants (Juneson et al. 2001; Sempere et al. 2011). From an industrial point of view, the choice of activated sludge as an inoculum presents advantages due to the ease of implementation and lower operational costs.

The purpose of this work is to investigate the removal of styrene from air emissions by using 2 types of bioreactors and to compare both procedures of inoculation on the basis of their influence on the system performance and the evolution of the microbial community. For this purpose, the following objectives have been taken into consideration: (1) to evaluate the behaviour of one BF packed with peat, another with coconut fibre and one BTF packed with plastic rings. The bioreactors were operated at several EBRTs and at a range of inlet concentrations representative of emissions from industries producing polystyrene; and (2) to analyse the effect on the systems of using 2 sources of inoculum: an enriched culture of the strain Pseudomonas putida CECT 324 in the BFs and activated sludge from a municipal wastewater treatment plant (WWTP) in the BTF. To the best of our knowledge, this is the first work which includes a 
comparison of the performance and microflora of bioreactors inoculated with an enriched culture or with an activated sludge. The microbial community was studied by fluorescence in situ hybridisation (FISH) and denaturing gradient gel electrophoresis analysis (DGGE).

\section{Materials and methods}

Inoculation procedures

The inoculation of the BFs was performed with $1 \mathrm{~L}$ of enriched culture of the strain Pseudomonas putida CECT 324 (named here as inoculum 1). The following protocol was developed for the inoculum preparation: (i) the strain Pseudomonas putida CECT 324 was supplied from the Spanish Type Culture Collection (CECT). This species was selected for the inoculation process since previous studies have reported that Pseudomonas putida is suitable for degrading styrene (Okamoto et al. 2003). (ii) The strain CECT 324 was grown in $50 \mathrm{~mL}$ sterile flasks containing $20 \mathrm{ml}$ of nutrient Broth/Agar II medium (composition: $1 \mathrm{~g} \mathrm{~L}^{-1}$ beef extract, $2 \mathrm{~g} \mathrm{~L}^{-1}$ yeast extract, $5 \mathrm{~g} \mathrm{~L}^{-1}$ peptone, $\left.5 \mathrm{~g} \mathrm{~L}^{-1} \mathrm{NaCl}, \mathrm{pH}: 7.2\right)$ at $30^{\circ} \mathrm{C}$ in a rotary shaker at $100 \mathrm{rpm}$ (New Brunswick scientific, Edison, USA). (iii) After 1 week, $250 \mathrm{ml}$ of the concentrated pure culture was introduced into one aerated batch reactor and diluted with $750 \mathrm{~mL}$ of nutrient Broth/Agar II medium. The batch reactor was aerated using non-sterile air and was continuously fed with styrene at a rate of $0.15 \mathrm{~mL} \mathrm{~h}^{-1}$ for a period of 30 days.

The inoculation of the BTF was performed with $1 \mathrm{~L}$ of activated sludge (named here as inoculum 2) from a municipal WWTP located in Quart-Benager (Valencia, Spain), which was continuously recirculated over the bed for a period of $24 \mathrm{~h}$. 
BFs set-up and operational conditions

Two lab-scale BFs were operated in parallel. One BF (BF1-P) was packed with fibrous peat (ProEco Ambiente, Spain) and another (BF2-C) with coconut fibre (Pure Air, Solutions, The Netherlands). The physical and chemical properties of these materials are shown in Table 1. The peat was acidic, so $\mathrm{pH}$ adjustment until neutral $\mathrm{pH}$ was achieved by using diluted sodium hydroxide solution prior to the start-up.

The schematic of the experimental set-up of the BFs is shown in Fig. 1a. Each BF was made from methacrylate, with a total length of $97 \mathrm{~cm}$, an internal diameter of $13.6 \mathrm{~cm}$ (volume of $14 \mathrm{~L}$ ) and was equipped with five sampling ports to measure VOC concentrations along the bed of the column, located at 0 (inlet port), 25, 50, 75 and 97 (outlet port) $\mathrm{cm}$ of column height. Four additional ports were used to extract packing material samples located at 20,40,60 and $80 \mathrm{~cm}$. A $10 \mathrm{~cm}$ head space was used for the waste gas inlet and for water/nutrient feed, while a $10 \mathrm{~cm}$ bottom space was used for the treated air outlet and leachate. Prior to introduction into the BFs, the compressed, filtered and dry air was passed through the humidifier to assure a relative humidity value of at least $90 \%$. The air stream was contaminated with styrene by using a syringe pump (New Era, infusion/withdraw NE 1000 model, USA) and fed to the BFs through the top of the column flowing downwards into the bed. The gas flow rate was adjusted by a mass flow controller (Bronkhorst Hi-Tec, The Netherlands).

The macro- and micro-nutrients were incorporated by pouring $50 \mathrm{ml}$ per day of a nutrient solution buffered at pH $7\left(22.4 \mathrm{~g} \mathrm{KNO}_{3} \mathrm{~L}^{-1}, 2.4 \mathrm{~g} \mathrm{KH}_{2} \mathrm{PO}_{4} \mathrm{~L}^{-1}, 0.4 \mathrm{~g} \mathrm{~K}_{2} \mathrm{HPO}_{4}\right.$

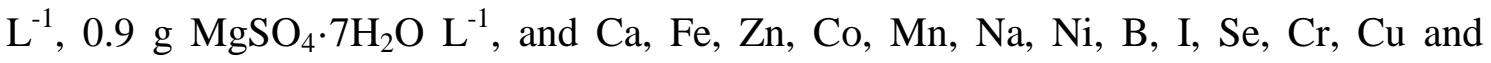
vitamins at trace doses). The moisture content of the packing material was controlled by 
adding 50 and $150 \mathrm{ml}$ per day of deionised water on top of the BF with peat and coconut fibre, respectively. This difference in the spraying volume was due to the fact that peat has a higher water-holding capacity than coconut fibre; $88 \%$ and $60 \%$ respectively.

The $2 \mathrm{BFs}$ were operated in parallel under different operational conditions for more than 5 months under continuous loading. Operational conditions in BFs are shown in Table 2. During the first 3 months, the BFs were operated at EBRTs between 90 and $120 \mathrm{~s}$ and ILs between 12 and $24 \mathrm{~g} \mathrm{~m}^{-3} \mathrm{~h}^{-1}$. After this period, four different stages (1-4) were performed. EBRTs were set at values of 45, 60 and $90 \mathrm{~s}$, and inlet concentrations ranged between 250 and $1300 \mathrm{mg} \mathrm{Nm}^{-3}$ (corresponding to ILs varying from 15 to $45 \mathrm{~g}$ $\mathrm{m}^{-3} \mathrm{~h}^{-1}$, Table 2). In-situ emissions from industries producing polystyrene were previously monitored and found to oscillate between 200 and $400 \mathrm{mg} \mathrm{Nm}^{-3}$. Therefore, the inlet concentrations tested on this work covered the typical values of the emissions coming from the industrial manufacturing of polystyrene. Each stage was carried out within a minimum period of 10 days.

BTF set-up and operational conditions

After ending the operation of the BFs, another experiment using a BTF was performed in order to compare the use of different bioreactors and inoculation procedures. The BTF was filled with polypropylene rings (Flexiring, Koch-Glitsch B.V.B.A., Belgium) of $25 \mathrm{~mm}$ nominal diameter and a surface area of $207 \mathrm{~m}^{2} \mathrm{~m}^{-3}$ whose physical characteristics are shown in Table 1 . The schematic of the experimental set-up of the BTF is shown in Fig. 1b. The BTF was built using 3 cylindrical methacrylate modules in series with a total bed length of $123 \mathrm{~cm}$ and an internal diameter of $14.4 \mathrm{~cm}$ (volume 
of $20 \mathrm{~L}$ ). The BTF was equipped with four sampling ports to measure styrene concentrations along the bed of the column, located at 0 (inlet port), 44, 86, and 123 (outlet port) $\mathrm{cm}$ of column height. Three additional ports were used to extract biofilm samples located at 20,63 and $105 \mathrm{~cm}$. The bioreactor was also provided with $20 \mathrm{~cm}$ of top and bottom free spaces. The compressed, filtered and dry air was contaminated with styrene using a syringe pump (New Era, infusion/withdraw NE 1000 model, USA). The polluted air stream was introduced through the bottom of the column and the flow rate was adjusted by a mass flow controller (Bronkhorst Hi-Tec, The Netherlands). A 3 L recirculation tank, partially renewed every week, was used to feed the recirculation solution into the bioreactor in counter-current mode with respect to the air flow using a centrifugal pump at $2.5-3 \mathrm{~L} \mathrm{minute}^{-1}$ for 15 minutes every $2 \mathrm{~h}$.

A nutrient solution buffered at $\mathrm{pH} 8\left(9.7 \mathrm{~g} \mathrm{NH}_{4} \mathrm{Cl} \mathrm{L}^{-1}, 0.9 \mathrm{~g} \mathrm{MgSO}_{4} \cdot 7 \mathrm{H}_{2} \mathrm{O} \mathrm{L}^{-1}\right.$,

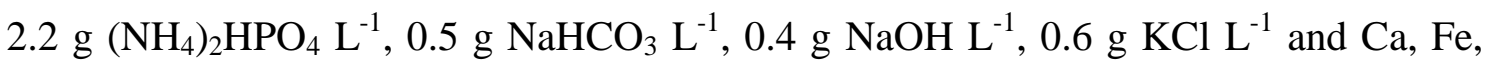
$\mathrm{Zn}, \mathrm{Co}, \mathrm{Mn}, \mathrm{Na}, \mathrm{Ni}, \mathrm{B}, \mathrm{I}, \mathrm{Se}, \mathrm{Cr}, \mathrm{Cu}$ and vitamins at trace doses) was supplied to the recirculation tank using a peristaltic pump. The nutrient solution flow rate was maintained at a mass ratio of carbon and nitrogen of 25 in order to assure that the nitrogen concentration in the recirculation solution was not limiting the biodegradation process, corresponding to a flow rate of nutrients between 32 and $160 \mathrm{~mL} \mathrm{~d}^{-1}$.

The BTF was operated for more than 5 months under continuous loading. Operational conditions applied to the BTF are shown in Table 2. In the first 20 days, an EBRT of $60 \mathrm{~s}$ and an inlet concentration of $200 \mathrm{mg} \mathrm{Nm}^{-3}$ were applied. Afterwards, 6 different stages (1-6) were performed over 5 months. In the first 3 stages, an EBRT of $60 \mathrm{~s}$ and inlet concentrations ranging between 300 and $468 \mathrm{mg} \mathrm{Nm}^{-3}$ were applied (Table 2). At stages 4 and 5, the EBRT was decreased from 60 to $45 \mathrm{~s}$. The maximum inlet concentration was applied $\left(475 \mathrm{mg} \mathrm{Nm}^{-3}\right)$ in stage 5. At stage 6, the EBRT was 
decreased to $30 \mathrm{~s}$ in order to evaluate the minimum EBRT that allows high RE and stable performance. Each stage was carried out for a minimum period of 20 days.

Analytical methods

The styrene concentration was measured using a total hydrocarbon analyser (Nira Mercury 901, Spirax Sarco, Spain). The inlet and outlet gas streams were monitored daily while the intermediate ports were monitored at a minimum of 2 times for each stage. The response factor of the total hydrocarbon analyser was determined by gas chromatograph (model 7890, Agilent Technologies, USA) equipped with a $1 \mathrm{~mL}$ automated gas valve injection system, a flame ionisation detector and an Rtx ${ }^{\circledR}$-VMS capillary column $(30 \mathrm{~m} \times 0.25 \mathrm{~mm} \times 1.4 \mu \mathrm{m})$. The gas carrier was helium at a flow rate of $1.3 \mathrm{~mL} \mathrm{~min}{ }^{-1}$. The injector, oven and detector temperatures were 250,100 and $240^{\circ} \mathrm{C}$, respectively. The pressure drop was monitored at a minimum of once a week (KIMO, MP101 model, Spain). The $\mathrm{CO}_{2}$ concentrations in the inlet and outlet gas streams were measured once a week using a CARBOCAP ${ }^{\circledR}$ carbon dioxide analyser (GM70 model, Vaisala, Finland).

The conductivity and $\mathrm{pH}$ of the leachate from $\mathrm{BFs}$ were determined daily (pH/Cond 340i, WTW, Germany) and the moisture content of the media was measured at a minimum of 2 times in each experimental stage using the dry weight method at 2 locations: at $20 \mathrm{~cm}$ from the inlet (top zone) and at $80 \mathrm{~cm}$ from the inlet (bottom zone). The conductivity and $\mathrm{pH}$ of the $\mathrm{BTF}$ recirculation solution were determined daily (pH/Cond 340i, WTW, Germany). In addition, the total organic carbon and inorganic carbon (TOC- $\mathrm{V}_{\mathrm{CHS}}$, Shimadzu, Japan), suspended solids (SS), volatile suspended solids 
(VSS) and $\mathrm{NO}_{3}{ }^{-}, \mathrm{NH}_{4}{ }^{+}$and $\mathrm{PO}_{4}{ }^{3-}$ concentrations were measured twice a week (Ionic Chromatograph 883 Basic IC Plus).

DNA isolation, PCR and DGGE

The presence of Pseudomonas putida in both BFs was checked by DGGE analysis. DNA was isolated from the pure culture of Pseudomonas putida CECT 324, from the enriched culture prior to inoculation (inoculum 1) and from the bed samples of each BF at 105, 142 and 156 days of operation. Bed samples were taken from the bottom port (located at $80 \mathrm{~cm}$ from the inlet). The DNA isolation was performed using a FastDNA Spin Kit for soil (MP Biomedicals, Illkirch, France) and was stored at $-20^{\circ} \mathrm{C}$ until analysis. The extracted DNA was amplified by PCR using 2 universal primers targeting the 16S rRNA gene for eubacteria: primer F357GC containing a CG clamp (5’CGCCCGCCGCGCGCGGCGGGCGGGGCGGGGGCACGGGGGGCCTACGGG AGGCAGCAG3') and primer R518 (5’ATTACCGCGGCTGCTGG3'). PCRs were performed in a thermal cycler (LongGene Scientific Instruments, Hangzhou) with a 50$\mu \mathrm{l}$ reaction volume of a mixture containing final concentrations of 1.25 units of Taq DNA polymerase, $0.2 \mathrm{mM}$ dNTPs, $2 \mathrm{mM} \mathrm{Mg}^{2+}$ and $0.5 \mu \mathrm{M}$ of each primer (EuroClone, Italy). PCR conditions (Muyzer and Ramsing, 1993) consisted of 20 cycles of: $94^{\circ} \mathrm{C}$ for 1 minute, $65^{\circ} \mathrm{C}$ for 1 minute, a touchdown annealing step of $0.5^{\circ} \mathrm{C}$ increments from $65^{\circ} \mathrm{C}$ to $55^{\circ} \mathrm{C}$ for 1 minute, and followed by $72^{\circ} \mathrm{C}$ for 3 minutes. For DGGE analysis, 20 $\mu 1$ of PCR product generated from each sample was separated on an $8 \%$ acrylamide gel running in a linear denaturant gradient increasing from $35 \%$ to $60 \%$ using a KuroGel Verti 2020 DGGE System (VWR international Eurolab S.L.). The gel was run at $60^{\circ} \mathrm{C}$ for 5 minutes at $50 \mathrm{~V}, 120$ minutes at $150 \mathrm{~V}$ and 60 minutes at $200 \mathrm{~V}$. 
Fluorescence in situ hybridisation (FISH)

The FISH technique was carried out adapting the procedure described by Amann et al. (2001). Bed samples from the bottom port of both BFs at day 105, 142 and 156 were analysed. Biofilm samples taken from the bottom port (located at $20 \mathrm{~cm}$ from the inlet) and the top port (located at $105 \mathrm{~cm}$ from the inlet) from BTF at day 65 and 165 were analysed. Inoculum samples of the BFs (inoculum 1) and the BTF (inoculum 2) were analysed as well.

The samples $(5 \mathrm{~mL}$ for the samples of the BFs, $1 \mathrm{~mL}$ for the BTF and the inoculum samples) were suspended in $15 \mathrm{ml}$ sterile distilled water and disaggregated with an Ultra-Turrax (IKA ${ }^{\circledR}$ T18 basic, Germany). The samples were fixed using the procedure described by Amann et al. (2001). According to the procedure, Gramnegative cells were fixed with $4 \%$ paraformaldehyde and Gram-positive cells with ethanol. Oligonucleotide probes targeting the phylogenetic groups Alphaproteobacteria, Betaproteobacteria, Gammaproteobacteria, Deltaproteobacteria, Firmicutes and Actinobacteria were analysed. Furthermore, the evolution of Pseudomonas sp. and Pseudomonas putida were monitored. An equimolar mixture of EUBI, EUBII, and EUBIII probes were used to detect all eubacteria. Probes sequences and their formamide percentage are summarised in Table 3 (Loy et al. 2007). In the hybridisation, the general EUB $_{\text {mix }}$ probe was labelled with $\mathrm{Cy} 5$, while taxonomic specific probes were labelled with Cy3-labelled (Thermo Fisher Scientific, Germany). Hybridisation was performed at $46^{\circ} \mathrm{C}$ for $2 \mathrm{~h}$. After the hybridisation step, slides were rinsed for 18 minutes at $48^{\circ} \mathrm{C}$, dried, mounted and examined using a confocal laser scanning microscope (FV 1000, Olympus, Japan). Specific probes were quantified as a proportion of EUB $_{\text {mix }}$-labelled 
bacteria using image analysis based on the methodology developed by Jubany et al. (2009).

\section{Results}

BF performance

The performance of the 2 BFs treating styrene emissions, BF1-P packed with peat and BF2-C with coconut fibre is shown in Fig. 2. At day 0, each BF was inoculated with the enriched culture of Pseudomonas putida CECT 324 (inoculum 1) whose suspended solid concentration and percentage of volatile suspended solids were $1.7 \mathrm{~g} \mathrm{~L}^{-1}$ and $71 \%$, respectively. Following inoculation, the bioreactors were operated during 84 days at mild conditions, corresponding to EBRTs between 90 and $120 \mathrm{~s}$ and inlet concentrations between 300 and $790 \mathrm{mg} \mathrm{Nm}^{-3}$, in order to develop a suitable active biofilm on the surface of the packing material. BF1-P showed a gradual increase in the removal efficiency (RE) until reaching 99\% on day 60 (Fig 2a). From this day, a progressive decrease in the removal of styrene occurred until day 64, from which REs fluctuated in $35 \pm 8 \%$. Pressure drop measurements in BF1-P showed a sudden increase on day 37

(Fig. 2c). The pressure drop rose from a value of 98 (day 37) to $490 \mathrm{~Pa} \mathrm{~m}^{-1}$ (day 41), and reached a maximum value of $931 \mathrm{~Pa} \mathrm{~m}^{-1}$ on day 52 indicating compaction of the bed (Fig. 2c). BF2-C showed a gradual increase in the RE until reaching $95 \%$ on day 52 (Fig. 2b). From days 53 to 84 , RE oscillated in $78 \pm 13 \%$. No bed compaction was detected in BF2-C, the pressure drop was maintained in stable values as low as $10 \mathrm{~Pa} \mathrm{~m}^{-}$ ${ }^{1}$ from days 1 to 84 (Fig. 2d). 
After nearly 3 months of operation, an EBRT of $60 \mathrm{~s}$ and an average inlet concentration of $372 \pm 14 \mathrm{mg} \mathrm{Nm}^{-3}$ were applied in both BFs (stage 1). During this stage, an average outlet concentration of $166 \pm 15 \mathrm{mg} \mathrm{Nm}^{-3}$ (RE of 55\%) was observed in BF1-P from day 84 to day 110 (Fig. 2a). On day 110 the pressure drop retained values as high as $800 \mathrm{~Pa} \mathrm{~m}^{-1}$ (Fig. 2c), so the reactor was opened to decompress the packing material. Upon restoration of operation, the pressure drop decreased to $170 \mathrm{~Pa}$ $\mathrm{m}^{-1}$ (Fig. 2c) and the RE increased to a value of 95\%. From day 110, RE was kept at values higher than $95 \%$ (average outlet concentration of $23 \pm 9 \mathrm{mg} \mathrm{Nm}^{-3}$ ) until the end of stage 1 (day 122). In the BF2-C, an outlet concentration of $106 \pm 20 \mathrm{mg} \mathrm{Nm}^{-3}$ (RE of $72 \%$ ) was observed for the whole stage 1 (Fig. 2b). The pressure drop in BF2-C was kept below $30 \mathrm{~Pa} \mathrm{~m}^{-1}$ for the entire stage 1 (Fig 2d).

Due to the different performances of both BFs at the end of stage 1 (with a higher RE for BF1-P than BF2-C), different values of EBRTs were chosen for stage 2. It was decided to lower the EBRT in BF1-P and increase it in BF2-C in order to determine the minimum EBRT that allows high efficiency in each system. In stage 2, BF1-P presented REs of $\sim 70 \%$ using inlet concentrations of $782 \pm 20 \mathrm{mg} \mathrm{Nm}^{-3}$ (EBRT of $60 \mathrm{~s}$ ). BF2-C showed REs $>90 \%$ (outlet concentrations below $40 \mathrm{mg} \mathrm{Nm}^{-3}$ ) using lower inlet concentrations (368 $\left.\pm 15 \mathrm{mg} \mathrm{Nm}^{-3}\right)$ and a higher EBRT (90 s).

In stage 3 , the same IL $\left(22 \mathrm{~g} \mathrm{~m}^{-3} \mathrm{~h}^{-1}\right)$ was applied in both BFs. The EBRT in BF1-P was decreased to $45 \mathrm{~s}$ and the inlet concentrations $\left(282 \pm 18 \mathrm{mg} \mathrm{Nm}^{-3}\right)$ were set to apply the same IL value as stage 1 , obtaining outlet concentrations of $14 \pm 10 \mathrm{mg}$ $\mathrm{Nm}^{-3}$ (RE of 95\%). The EBRT in BF2-C was maintained for $90 \mathrm{~s}$ and the inlet concentrations were increased to $585 \pm 18 \mathrm{mg} \mathrm{Nm}^{-3}$, reaching outlet concentrations below $110 \mathrm{mg} \mathrm{Nm}^{-3}$ (RE 80\%). At an IL of $22 \mathrm{~g} \mathrm{~m}^{-3} \mathrm{~h}^{-1}$, BF1-P working at an EBRT of $45 \mathrm{~s}$ achieved higher REs than BF2-C working at twice the EBRT. In stage 4, a 
maximum IL of $45 \mathrm{~g} \mathrm{~m}^{-3} \mathrm{~h}^{-1}$ was applied to both BFs maintaining the same EBRTs as in stage 3. The average inlet concentrations of $580 \pm 10$ and $1085 \pm 67 \mathrm{mg} \mathrm{Nm}^{-3}$ were applied in BF1-P and BF2-C, respectively. The RE decreased in both BFs: from 95 to $62 \%$ in BF1-P and from 80 to $47 \%$ in BF2-C. From day 148, pressure drops fluctuated between 637-784 $\mathrm{Pa} \mathrm{m}^{-1}$ (Fig. 2c) in BF1-P indicating the presence of compaction problems in the peat bed. Maximum pressure drop in BF2-C was $59 \mathrm{~Pa} \mathrm{~m}^{-1}$ (day 154 , Fig. 2d).

In BF1-P, the moisture content was maintained at $\sim 80 \%$ for both sampling ports (top and bottom) when EBRTs greater than $60 \mathrm{~s}$ were applied (stages 1-2, average value of $80.6 \pm 3.1 \%$, Fig. 2 c). On day 162 , the moisture content decreased until $63 \%$ in the top and $50 \%$ in the bottom after 24 days working at 45 s of EBRT (Fig. 2c). In BF2-C, the average moisture content in the start-up period was $51.4 \pm 7.4 \%$ and from day 84 the average moisture content was $66.6 \pm 6.5 \%$ and $70.6 \pm 11.4 \%$ in the top and bottom locations, respectively (Fig. 2d). The average $\mathrm{pH}$ of the leachate was $8.4 \pm 0.5$ and $8.8 \pm$ 0.3 in BF1-P and BF2-C, respectively. The average conductivity of the leachate was 3.8 \pm 1.9 and $6.2 \pm 1.5 \mathrm{mS} \mathrm{cm}^{-1}$ in BF1-P and BF2-C, respectively.

\section{BTF performance}

The performance of the BTF is shown in Fig. 3. At day 0, the BTF was inoculated with the activated sludge (inoculum 2), whose suspended solid concentration and percentage of volatile suspended solids were $7.3 \mathrm{~g} \mathrm{~L}^{-1}$ and $78 \%$, respectively. During the first 20 days, the system was operated at styrene inlet concentrations of $216 \pm 14 \mathrm{mg} \mathrm{Nm}^{-3}$ and an EBRT of $60 \mathrm{~s}$. After the first week, the BTF was able to reach a RE of 94\% (Fig. 3a). In stage 1, the inlet concentration was raised to a value of $290 \pm 12 \mathrm{mg} \mathrm{Nm}^{-3}$ and the RE 
was maintained at $\sim 90 \%$. In stages 2 and 3, average inlet concentrations of $391 \pm 13$ and $444 \pm 39 \mathrm{mg} \mathrm{Nm}^{-3}$ were applied, respectively. REs of $\sim 75 \%$ were obtained in both stages corresponding to average outlet concentrations of $99 \pm 28$ and $109 \pm 40 \mathrm{mg} \mathrm{Nm}^{-3}$, respectively. It is worth noting that on day 70 , the RE dropped to $62 \%$ because of the limitation of nutrients, since the phosphate concentration $\left(\mathrm{PO}_{4}{ }^{3-}\right)$ in the recirculation tank was $<1 \mathrm{mg}-\mathrm{P} \mathrm{L}^{-1}$ due to a maintenance failure. Afterwards, the phosphate concentration was kept $>30 \mathrm{mg}-\mathrm{P} \mathrm{L}^{-1}$ for the rest of the experiment. The RE was successfully recovered to $77 \%$ on day 75 (Fig. 3a). From stage 4, the EBRT was decreased to $45 \mathrm{~s}$ and average inlet concentrations of $355 \pm 50 \mathrm{mg} \mathrm{Nm}^{-3}$ (stage 4) and $512 \pm 15 \mathrm{mg} \mathrm{Nm}^{-3}$ (stage 5) were applied. Average outlet concentrations of $64 \pm 10 \mathrm{mg}$ $\mathrm{Nm}^{-3}$ and $115 \pm 25 \mathrm{mg} \mathrm{Nm}^{-3}$ (REs about 80\%) were obtained for stage 4 and 5 , respectively. In stage 6, the minimum tested EBRT was applied (30 s). The RE was $80 \%$ with an average outlet concentration of $45 \pm 11 \mathrm{mg} \mathrm{Nm}^{-3}$. The pressure drop was maintained in low values ranging between 1 and $60 \mathrm{~Pa} \mathrm{~m}^{-1}$ during the whole experimental period (Fig. 3b).

During the operation of the BTF, a liquid volume of $3 \mathrm{~L}$ was maintained in the recirculation tank with a weekly purge of $1.5 \mathrm{~L}$. Average values of $\mathrm{pH}$ and conductivity were $8.1 \pm 0.5$ and $7.3 \pm 2.4 \mathrm{mS} \mathrm{cm}{ }^{-1}$ (Fig. 3b). Average values of ammonium $\left(\mathrm{NH}_{4}^{+}\right)$, nitrate $\left(\mathrm{NO}_{3}{ }^{-}\right)$and phosphate $\left(\mathrm{PO}_{4}{ }^{3-}\right)$ concentrations were $24.6 \pm 16.0,1.7 \pm 2.9$ and $121.5 \pm 80.2 \mathrm{mg} \mathrm{L}^{-1}$, respectively. The average concentration of suspended solids was $480 \pm 408 \mathrm{mg} \mathrm{L}^{-1}$ with a percentage of volatile suspended solids of $83 \pm 8 \%$. The average amount of total organic carbon was $146 \pm 59 \mathrm{mg} \mathrm{C} \mathrm{L}^{-1}$. In all cases, solvent removal with the purge represented less than $1 \%$ of the total amount of added styrene during the week. Thus, the organic carbon in the purge was considered negligible for the evaluation of the BTF performance in terms of EC and RE. 
Relationship between EC and IL

The relationships between EC and IL calculated from the inlet to each intermediate sampling port (first quarter, half and three quarter of the BFs and the first third, half and two third of the BTF) and for the whole volume of the bioreactors are plotted in Fig. 4. The 3 bioreactors performed near complete degradation with an IL of $40 \mathrm{~g} \mathrm{~m}^{-3} \mathrm{~h}^{-1}$ for the whole range of tested EBRT. Maximum ECs of 81 and $39 \mathrm{~g} \mathrm{~m}^{-3} \mathrm{~h}^{-1}$ were obtained for BF1-P and BF2-C, respectively, with REs $\sim 45 \%$ (IL of $173 \mathrm{~g} \mathrm{~m}^{-3} \mathrm{~h}^{-1}$ at EBRT of 60 $\mathrm{s}$ in BF1-P, Fig. 4a; IL of $89 \mathrm{~g} \mathrm{~m}^{-3} \mathrm{~h}^{-1}$ at EBRT of $90 \mathrm{~s}$ in BF2-C, Fig. 4b). A maximum EC of $52 \mathrm{~g} \mathrm{~m}^{-3} \mathrm{~h}^{-1}$ was obtained for BTF with a RE of $45 \%$ (IL of $116 \mathrm{~g} \mathrm{~m}^{-3} \mathrm{~h}^{-1}$, EBRT of 45 s, Fig. 4c). The comparison of the behaviour of the 3 reactors when working at an EBRT of $60 \mathrm{~s}$ and an IL of $\sim 75 \mathrm{~g} \mathrm{~m}^{-3} \mathrm{~h}^{-1}$ indicates that BF1-P and BTF presented a similar value of EC $\sim 40 \mathrm{~g} \mathrm{~m}^{-3} \mathrm{~h}^{-1}$ (Fig. 4a,c) unlike BF2-C, which showed a lower EC of $\sim 30 \mathrm{~g} \mathrm{~m}^{-3} \mathrm{~h}^{-1}$ (Fig. 4b). By decreasing the EBRT to $45 \mathrm{~s}$, both BF1-P and BTF resulted in similar values with ECs of $\sim 55 \mathrm{~g} \mathrm{~m}^{-3} \mathrm{~h}^{-1}$ for an IL $\sim 85 \mathrm{~g} \mathrm{~m}^{-3} \mathrm{~h}^{-1}$ (Fig. 4a,c).

Carbon dioxide production

The evolution of $\mathrm{CO}_{2}$ production (calculated for the whole bed volume) as a function of the EC is presented in Fig. 5 for the 3 bioreactors. A proportional ratio exists between EC and $\mathrm{CO}_{2}$ production. Linear regressions for these data resulted in values of 2.57 , 2.81 and $2.34 \mathrm{~g} \mathrm{CO}_{2} / \mathrm{g}$ styrene in BF1-P (Fig. 5a), BF2-C (Fig. 5b) and BTF (Fig. 5c), respectively. These values are comparable to the ratio of $2.78 \mathrm{~g} \mathrm{CO}_{2} / \mathrm{g}$ styrene reported by Rene et al. (2010) by using a fungal monolith bioreactor. 
Assuming a general biomass composition formula of $\mathrm{C}_{5} \mathrm{H}_{7} \mathrm{O}_{2} \mathrm{~N}$, overall yield coefficients defined as $\mathrm{g}$ of dry biomass synthesised per gram of substrate consumed can be determined from the biodegradation reaction balance:

$$
\mathrm{aC}_{\mathrm{x}} \mathrm{H}_{\mathrm{y}} \mathrm{O}_{\mathrm{z}}+\mathrm{bO}_{2}+\mathrm{NH}_{3} \rightarrow \mathrm{C}_{5} \mathrm{H}_{7} \mathrm{O}_{2} \mathrm{~N}+\mathrm{cCO}_{2}+\mathrm{dH}_{2} \mathrm{O}
$$

resulting in values of $0.42,0.30$ and $0.54 \mathrm{~g}$ of dry biomass produced per $\mathrm{g}$ of styrene consumed for BF1-P, BF2-C and BTF, respectively. The greater yield coefficient observed in the BTF $\left(0.54 \mathrm{~g} \mathrm{~g}^{-1}\right)$ indicates that a higher biomass growth occurred. This fact could be associated with the trickling liquid that allows better control of parameters such as $\mathrm{pH}$ and better distribution over the bed of nutrients and substrates.

Microbiological studies

Denaturing gradient gel electrophoresis (DGGE)

DGGE was applied in order to check the presence of Pseudomonas putida in the BFs. Fig. 6 shows the DGGE banding patterns of samples from: the pure culture (Pseudomonas putida CECT 324), the enriched culture of strain CECT 324 prior to inoculation (inoculum 1) and the samples from BFs at days 105, 142 and 156 of operation. DGGE patterns showed 3 dominants bands for the pure culture (bands A, B and C; Fig. 6, lane 1). Similar band intensities of bands A, B and C, corresponding to Pseudomonas putida CECT 324, were detected in the enriched culture sample (inoculum 1; Fig. 6, lane 2). In addition, 2 new bands D and E appeared in the inoculum 1 (Fig. 6, lane 2). In contrast bands corresponding to Pseudomonas putida CECT 324 did not appear as a dominant species in the BF samples (Fig 6, lanes 3-8). BF samples containing multiple DGGE bands, some of them differed for each sample, although 
some common bands were detected. The bands D, G, H and I were observed for all BF1-P samples over the time period tested, while band J appeared by days 142 and 156 (Fig. 6, lanes 3, 5,7). Bands D, H, I, J, K, L were observed for all BF2-C samples, and relative intensities of the bands changed between different sampling times (Fig. 6, lanes 4, 6,8). For instance, bands $\mathrm{H}$ and I increased at day 142 (Fig. 6, lane 6) and decreased by day 156 (Fig. 6, lane 8). A new band M appeared by days 142 and 156 (Fig. 6, lanes 6,8) for BF2-C and by day 156 (Fig.6, lane 7) for BF1-P. At the end of the experiment, both BFs presented 5 common dominant bands (D, H, I, J, M; Fig. 6, lanes 7,8).

Monitoring of the bacterial community by fluorescence in situ hybridisation (FISH)

The monitoring of the bacterial community was carried out by FISH for the 2 inoculum and the 2 BFs: days 105 (stage 1), 142 (stage 3) and 156 (stage 4); and for the BTF: days 65 (stage 2, top and bottom zones) and 165 (stage 6, top and bottom zones). The total percentages of all target phyla were 76.5 and $98.4 \%$ for inoculum 1 and inoculum 2, respectively (Fig. 7, a,b,c). Total percentages of all target phyla ranged from 92.0 to $96.6 \%, 55.0$ to $64.9 \%$, and 88.8 to $98.8 \%$ for BF1-P, BF2-C and BTF, respectively (Fig. 7a,b,c). In all samples, the phylum Proteobacteria (Alphaproteobacteria, Betaproteobacteria, Gammaproteobacteria and Deltaproteobacteria) was more abundant than the phyla Firmicutes and Actinobacteria. Among bacterial groups from both inocula, members of the Gammaproteobacteria (inoculum 1: $30.6 \%$ and inoculum 2: 37.1\%; Fig. 7a,c) followed by Alphaproteobacteria (inoculum 1: $25.8 \%$ and inoculum 2: $20.5 \%$; Fig. 7a,c) were the most abundant groups. Inoculum 2 showed a higher proportion of Betaproteobacteria (14.4\%), Firmicutes (10.5\%) and Actinobacteria (10.6\%) (Fig. 7c). Regarding the evolution of the bacterial groups, their 
composition changed over time. For BF1-P, Alphaproteobacteria (32.5\%), and Gammaproteobacteria (22.4\%) were the most abundant groups on day 105, but they declined on day 142 in which more abundance of Actinobacteria (26.5\%) and Deltaproteobacteria (23.2\%) was observed (Fig. 7a). On day 156, Gammaproteobacteria (37.0\%) predominated among other phylogenetic groups. For BF2-C, Alphaproteobacteria (16.3\%) and Gammaproteobacteria (16.2\%) were the most abundant groups by day 105 (Fig. 7b). However, the abundance of Alphaproteobacteria (7.8\%) declined on day 142, and Gammaproteobacteria (17.5\%) and Betaproteobacteria, (13.1\%) were the most abundant groups. At the end of the experiment (day 156), there was a predominance of Gammaproteobacteria (20.4\%). For the BTF, Gammaproteobacteria (bottom: 41.7\%; top: 43.7\%) was the most abundant group on day 65, with slightly higher values than in the inoculum 2 (Fig. 7c). As shown in Fig. 7c, a predominance of Gammaproteobacteria was maintained (bottom: $24.8 \%$; top: $30.6 \%$ ) till the end of the experiment (day 165), but with a lower relative abundance. Similar results in relative abundances of phylogenetic groups from the bottom and top of the BTF for each sampling day showed that the bacterial community was quite homogeneous along the BTF.

Regarding the relative abundance of Pseudomonas putida, the enriched culture (inoculum 1) showed an abundance of $25.1 \%$ (Fig. 7d), while the activated sludge from a municipal WWTP (inoculum 2) showed a percentage of $1.0 \%$ (Fig. 7f). A different evolution of percentages of Pseudomonas putida over time was observed for both inoculation procedures. In the BFs, the relative abundance of this species was lower than in the inoculum. For BF1-P the relative abundance was $14.7 \%, 8.1 \%$ and $24.8 \%$ on days 105 (stage 1), 142 (stage 3) and 156 (stage 4), respectively (Fig. 7d). For BF2, a gradual decrease from a value of $25.1 \%$ in the inoculum 1 to $9.2 \%$ in stage 4 for BF2-C 
was observed (Fig. 7e). In BTF, the relative abundance of Pseudomonas putida increased from a value of $1.0 \%$ in the inoculum 2 to $14.1 \%$ and $7.7 \%$ in stage 6 in the bottom and top, respectively (Fig. 7f).

\section{Discussion}

Two inoculation procedures were compared on the basis of their influence on the performance and the microflora of two types of bioreactors (biofilter and biotrickling filter) in the removal of styrene from air emissions. A slow start-up was observed for the 2 biofilters packed with peat and coconut fibre and inoculated with an enriched culture of Pseudomonas putida CECT 324 (inoculum 1). The adaptation period lasted for 60 days (BF1-P) and 52 days $(\mathrm{BF} 2-\mathrm{C})$ during which the styrene RE gradually increased from nearly zero removal up to $99 \%$ for BF1-P and $95 \%$ for BF2-C, respectively (Fig. 2a,b). Other authors have studied styrene removal by using biofilters inoculated with activated sludge and reported shorter adaptation periods. Arnold et al. (1997) only needed 12 days to achieve $80 \%$ RE with inlet concentrations ranging from 50 to $115 \mathrm{mg} \mathrm{m}^{-3}$ in a peat BF inoculated with enriched bacteria obtained from activated sludge of a petrochemical plant. Bina et al. (2004) observed that during a start-up period with inlet concentrations of $315 \pm 51 \mathrm{mg} \mathrm{Nm}^{-3}$ and EBRT of $360 \mathrm{~s}$, the RE attained $80 \%$ at day 6 in a yard waste compost BF inoculated with activated sludge from municipal WWTP. The slower adaptation period in our work cannot be related to the different inlet concentration, both authors obtained adaptation periods shorter than 2 weeks by using lower or similar inlet concentrations than those used in the present work

(540 $\mathrm{mg} \mathrm{Nm}^{-3}$ for days 1 to 20 and $350 \mathrm{mg} \mathrm{Nm}^{-3}$ for days 21 to 60; Fig. 2a,b). It can be inferred that in spite of using a strain of Pseudomonas putida cultivated during 30 days 
with styrene as a sole carbon source, this inoculation strategy resulted in longer adaptation periods in comparison with using inocula from activated sludge coming from petrochemical or from municipal WWTP. This fact was corroborated by comparing results of BFs and the BTF. In the BTF, a start-up period as short as 7 days was observed by using activated sludge from municipal WWTP as inoculum. The shortness of the adaptation period in comparison with that obtained in the BFs could be associated to the high bacterial diversity of the activated sludge used as inoculum in BTF.

The results obtained in our study demonstrate that these 2 types of bioreactors have a good capacity to remove styrene gas emissions at the typical inlet concentrations of emissions from industries producing polystyrene. At inlet concentrations varying from 200 to $400 \mathrm{mg} \mathrm{Nm}^{-3}$, REs between 70 and $95 \%$ were obtained in the 3 bioreactors (outlet emissions values ranged between 15 and $125 \mathrm{mg} \mathrm{Nm}^{-3}$ ), demonstrating its suitability as an end-of-pipe control technique.

The comparison of the performance of the 2 biofilters indicates that BF1-P showed higher REs than those observed in BF2-C, even when the peat biofilter operated at half the value of EBRT than coconut biofilter. For example, at stage 3 for an IL of 22 $\mathrm{g} \mathrm{m}^{-3} \mathrm{~h}^{-1}$, BF1-P presented a RE of $95 \%$ with an EBRT of $45 \mathrm{~s}$ and BF2-C showed a RE of $80 \%$ with EBRT of $90 \mathrm{~s}$. A maximum EC of $81 \mathrm{~g} \mathrm{~m}^{-3} \mathrm{~h}^{-1}$ (RE of $45 \%$, Fig. 4a) was obtained in the peat BF at EBRTs of $60 \mathrm{~s}$ while a maximum EC of $39 \mathrm{~g} \mathrm{~m}^{-3} \mathrm{~h}^{-1}$ (RE of 45\%, Fig. 4b) was achieved in the coconut fibre BF, but at a higher EBRT of $90 \mathrm{s.}$ Juneson et al. (2001) reported ECs between 69 and $118 \mathrm{~g} \mathrm{~m}^{-3} \mathrm{~h}^{-1}$ (REs ranged from 65 to $75 \%$ ) by using a BF packed with composted wood bark and yard waste working at EBRTs ranged between 30 and 60 s. Dehghanzadeh et al. (2005) observed maximum ECs of 39 and $27 \mathrm{~g} \mathrm{~m}^{-3} \mathrm{~h}^{-1}$ (REs of $63 \%$ and $43 \%$, respectively) for EBRTs of 60 and 30 $\mathrm{s}$, in a BF packed with yard waste compost mixed with shredded hard plastics. Dion St- 
Pierre et al. (2009) obtained a maximum EC of $105 \mathrm{~g} \mathrm{~m}^{-3} \mathrm{~h}^{-1}(\mathrm{RE}$ of $80 \%)$ at an EBRT of $55 \mathrm{~s}$ in a BF filled with inorganic media. The maximum EC obtained in the peat biofilter is included in the range reported by Juneson et al. (2001) and is slightly lower than the maximum EC observed by Dion St-Pierre et al. (2009). The coconut fibre biofilter, which had a lower maximum EC than the obtained in the peat one, presented a maximum EC similar as those reported by Dehghanzadeh et al. (2005), although in our study the biofilter with coconut media operated at higher EBRTs.

Elimination capacity of styrene differed for the 2 packing materials tested (peat and coconut fibre) due to their differences in chemical and physical properties. Peat has a higher specific surface area, $13.4 \mathrm{~m}^{2} \mathrm{~g}^{-1}$, and water holding capacity, $88 \%$, than coconut fibre, $0.9 \mathrm{~m}^{2} \mathrm{~g}^{-1}$ and $60 \%$, respectively. Higher specific surface area is favourable for biofilm growth, allowing higher elimination capacities to be achieved. Although the peat biofilter achieved higher removal capacities than the coconut fibre biofilter, one of the main operational costs in a full scale bioreactor is the energy consumption in the blower related to the pressure drop in the bed. The main drawback of using peat media is the fast bed compaction problems which tended to lead to high pressure drops. In this study, compaction problems were detected during day 37, with an increase of 5-fold pressure drop by day 41 (from 98 to $490 \mathrm{~Pa} \mathrm{~m}^{-1}$; Fig. 2c). Bed compaction in a laboratory-scale biofilter can be easily solved by opening the biofilter to decompress the bed (pressure drops decreased from 800 to $170 \mathrm{~Pa} \mathrm{~m}^{-1}$ on day 110 ), but this maintenance strategy is difficult to implement on industrial full scale biofilters. The industrial use of peat media would demand a careful control of water spraying and/or periodic turns to keep pressure drop controlled at low values. The coconut fibre did not show this compaction problem, pressure drop slightly increased with time, but values were kept $<59 \mathrm{~Pa} \mathrm{~m}^{-1}$ for the whole experimental period. From the point of view 
of energy consumption, coconut fibre showed lower consumption and a more reliable performance, making it more suitable for industrial application. However, due to the low water holding capacity of the coconut fibre, BF2-C demanded a high water addition $(150 \mathrm{~mL} /$ day) to avoid excessive drying.

The BTF presented a maximum EC of $52 \mathrm{~g} \mathrm{~m}^{-3} \mathrm{~h}^{-1}$ (RE of $45 \%$ ) working at an EBRT of $45 \mathrm{~s}$ (Fig. 4c). Novak et al. (2008) reported a maximum EC of $11.3 \mathrm{~g} \mathrm{C} \mathrm{m}^{-3} \mathrm{~h}^{-1}$ (RE of $61 \%$ ) in a BTF packed with polypropylene Pall rings working with an EBRT of 35s. Sempere et al. (2011) obtained a maximum EC of $57.6 \mathrm{~g} \mathrm{~m}^{-3} \mathrm{~h}^{-1}$ (RE of $88.3 \%$ ) at an EBRT of $60 \mathrm{~s}$ in a BTF packed with Flexiring. The maximum EC obtained for the BTF in this study is a $10 \%$ lower than the maximum value observed by Sempere et al. (2011), but the EBRT in this study is lower. In terms of styrene removal, the BTF of this study showed a similar performance compared to the peat biofilter and a better performance than coconut fibre biofilter. Regarding pressure drop, values in the BTF were always kept below $59 \mathrm{~Pa} \mathrm{~m}^{-1}$ (Fig $3 \mathrm{~b}$ ). In terms of energy consumption, the BTF presented similar values of pressure drop as the coconut fibre BF and substantially lower than the peat BF. Moreover, BTF units can be cost-effective built in 8-10 m heights due to the low density and structural strength of the plastic packing materials while the usual bed height in $\mathrm{BF}$ units ranges from 1 to $2 \mathrm{~m}$. This enables the construction of BTF units with smaller footprints than BF units. In conclusion, BTFs appear to be the optimal option, combining factors of styrene removal capacity, energy consumption and requirements of footprint.

From the results regarding styrene removal, similar styrene removals were obtained by using both an enriched culture of the strain Pseudomonas putida CECT324 in a BF1-P and activated sludge from a WWTP in a BTF. Therefore, no advantage in using pure cultures for inoculation of bioreactors would be obtained. In addition, application of 
activated sludge for start-up of bioreactors in full scale would be practical and economical instead of using pure or enriched consortium (Bina et al. 2004).

The influence on the microflora of the 2 inoculation procedures was analysed by DGGE and FISH. Although 3 bands were observed for the pure culture Pseudomonas Putida CECT324 in the DGGE gel, these multiple bands can be attributed to different alleles within the same strain. For example, the sequenced genome of the strain Pseudomonas putida KT2440 revealed two alleles differing by only one nucleotide in the region amplified by DGGE which produced two bands (Bodilis et al. 2012). These authors pointed out that many Pseudomonas strains had at least two different $16 \mathrm{~S}$ rRNA alleles. Further, heteroduplexes have been observed in DGGE gels as potential PCR artifacts, thereby producing false positive bands for pure bacterial isolates. The banding patterns of DGGE for the enriched culture used for start-up of the BFs (inoculum 1) revealed that Pseudomonas Putida CECT324 was preserved after 30 days of cultivation under non-sterile aerated conditions, but other species appeared to have contaminated the culture ( 2 new dominant bands). This demonstrates that these other species could survive and grow in an environment with styrene as the sole carbon substrate. Although nutrient broth was used as the initial media for cultivation, only styrene was used as the carbon source during 30 days of cultivation. Among BFs samples, only one species from the inoculum survived in all samples, but the strain Pseudomonas Putida CECT324 was not detected in further sampling time points. DGGE fingerprints for BFs indicate that they were colonized by complex communities that changed over time. As Cabrol et al. (2011) points out, in the case of organic packing material (already colonized by endogenous microflora), both the inoculation and the operating conditions are sufficient to induce substantial modifications of the endogenous community structure. These authors indicated that emergence of species which were not detected in 
the inoculum proceeded from (a) the inoculum wherein their abundance was below detection limit, or (b) the endogenous reservoir of the organic packing material, and/or (c) the polluted gaseous effluent. The bands appearing in only one of the BFs (F, G for BF1-P, and K, L for BF2-C, Fig. 6) could indicate origin from the packing material. The largest number of common bacterial populations in both BFs (bands D, H, I, J, M, Fig. 6), which occurred at the end of the experiment, could suggest that the origin of these species were in the inoculum or in the polluted gaseous effluent. The polluted gaseous effluent constituted itself a cross-inoculation mechanism between both BFs.

FISH results showed that the phylum Proteobacteria represented more than half of the total fluorescence obtained by the general eubacterial probes in every sample. It is worth noting that bacteria from the phylum Proteobacteria have previously been identified as the dominant phyla in BTFs degrading mixtures of VOCs including styrene (Lebrero et al. 2012; Li et al. 2012). Gammaproteobacteria was detected as a large fraction in all samples. In BFs, members of the other Proteobacterial classes (Alphaproteobacteria, Betaproteobacteria, Gammaproteobacteria and Deltaproteobacteria), Firmicutes and Actinobacteria showed variations of dominant phylogenetic groups over time between both BFs. This can be explained on the basis of the dynamic changes of the community structure related to the different packing material used in BF1-P and BF2-C and the variations in the operational conditions. Although FISH data showed a large percentage of Pseudomonas putida in both BFs (ranging between 8.1 to $24.8 \%$ ), DGGE revealed that Pseudomonas putida CECT324 was not a dominant strian in the BFs since day 105 (after the acclimatisation period) till the end of the experiment. This suggests that other strains of Pseudomonas putida proliferated in the BFs instead of the pure culture strain chosen for the start-up. Surprinsingly by day 65 , the BTF samples showed little differences in the relative 
predominance of the Proteobacterial classes (Alphaproteobacteria, Betaproteobacteria, Gammaproteobacteria and Deltaproteobacteria), Firmicutes and Actinobacteria with the activated sludge used as inoculum. The similarity in relative abundances of detected phylogenetic groups from the inoculum and samples from day 65 can be explained by the fact that the BTF was filled with plastic rings, which can be considered as a negligible source of endogenous microflora. This is a surprising result; large variations in the relative abundance of phylogenetic groups will be expected after 65 days of exposure to styrene. Although the activated sludge used as an inoculum of the BTF contains only $1 \%$ of Pseudomonas putida as detected by FISH, the percentage of this species increased over time, reaching values of $14.1 \%$ (bottom) and $9.8 \%$ (top). These values are within the range of the abundance of Pseudomonas putida found in BFs. This demonstrates that Pseudomonas putida can grow to substantial abundances in a styrene degrading environment, independently of the inoculum source and the packing material (organics or plastic).

\section{Acknowledgements}

The research leading to these results has received funding from the People Programme (Marie Curie Actions) of the European Union's Seventh Framework Programme FP7/2007-2013/ under REA grant agreement $\mathrm{n}^{\mathrm{o}}$ 284949. Financial support from Ministerio de Economía y Competitividad (Project CTM2010-15031/TECNO) and Generalitat Valenciana (PROMETEO/2013/053), Spain, is also acknowledged. M.C.Pérez acknowledges the Ministerio de Educación, Cultura y Deporte, Spain for her FPU contract (AP2009-2645). 


\section{References}

Amann R, Fuchs BM, Behrens S (2001) The identification of microorganisms by fluorescence in situ hybridisation. Curr Opin Biotechnol 12: 231-236

Arnold M, Reittu A, von Wright A, Martikainen PJ, Suihko M-L (1997) Bacterial degradation of styrene in waste gases using a peat filter. Appl Microbiol Biotechnol 48: 738-744

Bina B, Dehghanzadeh R, Pourmoghadas H, Kalantary A, Torkian A (2004) Removal of styrene from waste gas stream using a biofilter. J Res Med Sci 6: 280-288

Bodilis J, Nsigue-Meilo S, Besaury L, Quillet L (2012) Variable copy number, intragenomic heterogeneities and lateral transfers of the 16S rRNA gene in Pseudomonas. Plos one 7(4): 1-14

Cabrol L, Malhautier L (2011) Integrating microbial ecology in bioprocess understanding: the case of gas biofiltration. Appl Microbiol Biotechnol 90: 837849

Cabrol L, Malhautier L, Poly F, Lepeuple AS, Fanlo JL (2012) Bacterial dynamics in steady-state biofilters: beyond functional stability. FEMS Microbiol Ecol 79: $260-271$

Dehghanzadeh R, Torkian A, Bina B, Poormoghaddas H, Kalantary A (2005) Biodegradation of styrene laden waste gas stream using a compost-based biofilter. Chemosphere 60: 434-439

Derwent RG, Jenkin ME, Saunders SM (1996) Photochemical ozone creation potentials for a large number of reactive hydrocarbons under European conditions. Atmos Environ 30: 181-199 
Dion St-Pierre MC, Avalos A, Heitz M (2009) Biofiltration of air contaminated by styrene vapors on inorganic filtering media: an experimental study. J Air Waste Manage Assoc 59: 568-578

International Agency for Research on Cancer (IARC) (1987) IARC Monographs on the Evaluation of Carcinogenic Risks to Humans. Overall Evaluations of Carcinogenicity: An Updating of IARC Monographs Volumes 1 to 42. Supplement 7. World Health Organization. Lyon, France

Ivanpour R, Cox HHJ, Deshusses MA, Schroeder ED (2005) Literature review of air pollution control biofilters and biotrickling filters for odor and volatile organic compound removal. Environ Prog 24: 254-267

Jang JH, Hirai M, Shoda M (2004) Styrene degradation by Pseudomonas sp. SR-5 in biofilters with organic and inorganic packing materials. Appl Microbiol Biotechnol 65: 349-355

Jubany I, Lafuente J, Carrera J, Baeza JA (2009) Automated thresholding method (ATM) for biomass fraction determination using FISH and confocal microscopy. J Chem Technol Biotechnol 84: 1140-1145

Juneson C, Ward OP, Singh A (2001) Microbial treatment of a styrene-contaminated air stream in a biofilter with high elimination capacities. J Ind Microbiol Biot 26: 196-202

Kennes C, Rene ER, Veiga MC (2009) Bioprocesses for air pollution control. J Chem Technol Biotechnol 84: 1419-1436

Kennes C, Veiga MC (2013) Biotrickling filters. In: Kennes C and Veiga MC (eds) Air pollution prevention and control, 1st edn. Wiley, United Kingdom, pp 121-138 
Kim J, Ryu HW, Jung DJ, Cho KS (2005) Styrene degradation in a polyurethane biofilter inoculated with pseudomonas sp.IS-3. J Microbiol Biotechnol 15: 12071213

Kolstad HA, Juel K, Olsen J, Lynge E (1995) Exposure to styrene and chronic health effects: mortality and incidence of solid cancers in the Danish reinforced plastics industry. Occup Environ Med 52: 320-327

Lebrero R, Rodriguez E, Estrada JM, Garcia-Encina PA, Muñoz R (2012) Odor abatement in biotrickling filters: effect of the EBRT on methyl mercaptan and hydrophobic VOCs removal. Bioresour Technol 109: 38-45

Li J, Ye G, Sun D, An T, Sun G, Liang S (2012) Performance of a biotrickling filter in the removal of waste gases containing low concentrations of mixed VOCs from a paint and coating plant. Biodegradation 23(1): 177-187

Loy A, Maixner F, Wagner M, Horn M (2007) probeBase - an online resource for rRNA-targeted oligonucleotide probes: new features 2007. Nucleic Acids Res 35: D800-D804

Malhautier L, Khammar N, Bayle S, Fanlo JL (2005) Biofiltration of volatile organic compounds. Appl Microbiol Biotechnol 68: 16-22

Muyzer G, Ramsing N (1993) Profiling of complex microbial populations by denaturing gradient gel electrophoresis analysis of polymerase chain reaction-amplified genes coding for 16S rRN. Appl Environ Microb 59: 695-700

Novak J, Paca J, Halecky M, Socco CR (2008) Styrene biofiltration in a trickle-bed reactor. Braz Arch Biol Techn 51(2): 385-390

Okamoto K, Izawa M, Yanase H (2003) Isolation and application of a styrene-degrading strain of Pseudomonas putida to biofiltration. J Biosci Bioeng 95: 633-636 
Paca J, Koutsky B, Maryska M, Halecky M (2001) Styrene degradation along the bed height of perlite biofilter. J Chem Technol Biotechnol 76: 873-878

Rene ER, Lopez ME, Veiga MC, Kennes C (2010) Performance of a fungal monolith bioreactor for the removal of styrene from polluted air. Bioresour Technol 101: 2608-2615

Shareefdeen Z, Singh A (2005) Biotechnology for odor and air pollution control. Springer, Heidelberg, Germany, pp 131

Sempere F, Gabaldon C, Martinez-Soria V, Marzal P, Penya-roja JM, Alvarez-Hornos FJ (2008) Performance evaluation of a biotrickling filter treating a mixture of oxygenated VOCs during intermittent loading. Chemosphere 73: 1533-1539

Sempere F, Martinez-Soria V, Palau J, Penya-roja JM, San Valero P, Gabaldon C (2011) Effects of nitrogen source and empty bed residence time on the removal of styrene gaseous emissions by biotrickling filtration. Bioproc Biosyst Eng 34: $859-867$

United States Environmental Protection Agency (USEPA) (1994) OPPT fact sheets, styrene fact sheets: support document, US-EPA 749- F95-019a 
Table 1 Physical and chemical properties of packing materials.

\begin{tabular}{lcc}
\hline & Peat & Coconut fibre \\
\hline $\mathrm{pH}$ & 4.8 & 6.8 \\
Water-holding capacity, \% & 88.0 & 60.0 \\
Bulk density, $\mathrm{kg} \mathrm{m}^{-3}$ & 133.0 & 60.0 \\
Organic matter content, \% & 95.0 & 93.8 \\
Specific surface area BET, $\mathrm{m}^{2} \mathrm{~g}^{-1}$ & 13.4 & 0.9 \\
Chemical analysis: & & \\
Carbon, \% & 48.5 & 47.8 \\
Hydrogen, \% & 5.8 & 5.8 \\
Oxygen, \% & 40.0 & 42.8 \\
Nitrogen, \% & 0.6 & 0.1 \\
Sulphur, \% & 0.1 & 0.0 \\
\hline \multicolumn{2}{c}{ Flexiring rings } \\
\hline Specific surface area, $\mathrm{m}^{2} \mathrm{~m}^{-3}$ & \multicolumn{2}{c}{207.0} \\
Void fraction, \% & \multicolumn{2}{c}{71.0} \\
Bulk density, Kg m ${ }^{-3}$ & \multicolumn{2}{c}{25.0} \\
Ring diameter, mm & \multicolumn{2}{c}{} \\
\hline
\end{tabular}


Table 2 Operational conditions in both BFs and in BTF for the removal of styrene.

\begin{tabular}{|c|c|c|c|c|c|c|c|c|}
\hline & Stages & Start-up & 1 & 2 & 3 & 4 & & \\
\hline \multirow{4}{*}{$\begin{array}{l}\text { BF1 } \\
\text { Peat }\end{array}$} & day & $0-84$ & $84-122$ & $122-138$ & $138-152$ & $152-162$ & & \\
\hline & $\begin{array}{l}\text { Inlet conc., } \\
\text { mg Nm}^{-3}\end{array}$ & $300-790$ & 335 & 750 & 275 & 560 & & \\
\hline & EBRT, s & $90-120$ & 60 & 60 & 45 & 45 & & \\
\hline & $\mathrm{IL}, \mathrm{g} \mathrm{m}^{-3} \mathrm{~h}^{-1}$ & $12-24$ & 22 & 45 & 22 & 45 & & \\
\hline \multirow{5}{*}{$\begin{array}{c}\text { BF2 } \\
\text { Coconut } \\
\text { fibre }\end{array}$} & day & $0-84$ & $84-114$ & 114-129 & $129-142$ & $142-162$ & & \\
\hline & $\begin{array}{l}\text { Inlet conc., } \\
\text { mg Nm}^{-3}\end{array}$ & $300-790$ & 335 & 375 & 550 & 1125 & & \\
\hline & EBRT, s & $90-120$ & 60 & 90 & 90 & 90 & & \\
\hline & IL, $\mathrm{g} \mathrm{m}^{-3} \mathrm{~h}^{-1}$ & $12-24$ & 22 & 15 & 22 & 45 & & \\
\hline & Stages & Start-up & 1 & 2 & 3 & 4 & 5 & 6 \\
\hline \multirow{4}{*}{$\begin{array}{l}\text { BTF } \\
\text { Flexiring } \\
\text { rings }\end{array}$} & day & $0-20$ & $20-45$ & $45-67$ & $67-87$ & $87-109$ & $109-133$ & $133-155$ \\
\hline & $\begin{array}{l}\text { Inlet conc., } \\
\text { mg Nm}^{-3}\end{array}$ & 200 & 300 & 375 & 468 & 350 & 475 & 180 \\
\hline & EBRT, s & 60 & 60 & 60 & 60 & 45 & 45 & 30 \\
\hline & $\mathrm{IL}, \mathrm{g} \mathrm{m}^{-3} \mathrm{~h}^{-1}$ & 12 & 18 & 22 & 28 & 28 & 38 & 22 \\
\hline
\end{tabular}


Table 3 List of oligonucleotide probes used in this study

\begin{tabular}{|c|c|c|c|}
\hline Probe & Specificity & Sequence $\left(5^{\prime}-3^{\prime}\right)$ & Formamide $(\%)$ \\
\hline$\overline{\text { EUB338 }^{\mathrm{a}}}$ & Most Bacteria & GCTGCCTCCCGTAGGAGT & $0-50$ \\
\hline EUB338-II ${ }^{\mathrm{a}}$ & $\begin{array}{l}\text { Other Bacteria not detected by } \\
\text { EUB338 }\end{array}$ & GCAGCCACCCGTAGGTGT & $0-50$ \\
\hline EUB338-III $^{\mathrm{a}}$ & $\begin{array}{l}\text { Other Bacteria not detected by } \\
\text { EUB338 }\end{array}$ & GCTGCCACCCGTAGGTGT & $0-50$ \\
\hline ALF968 & $\alpha$-Proteobacteria & GGTAAGGTTCTGCGCGTT & 20 \\
\hline BET42A & $\beta$-Proteobacteria & GCCTTCCCACTTCGTTT & 35 \\
\hline- & Competitor for BET42A & GCCTTCCCACATCGTTT & 35 \\
\hline GAM42A & $\gamma$-Proteobacteria & GCCTTCCCACATCGTTT & 20 \\
\hline- & Competitor for GAM42A & GCCTTCCCACTTCGTTT & 20 \\
\hline DELTA495A & $\delta$-Proteobacteria & AGTTAGCCGGTGCTTCCT & 35 \\
\hline DELTA495B $^{\mathrm{b}}$ & $\delta$-Proteobacteria & AGTTAGCCGGCGCTTCCT & 35 \\
\hline DELTA495C & $\delta$-Proteobacteria & AATTAGCCGGTGCTTCCT & 35 \\
\hline- & Competitor for DELTA495A & AGTTAGCCGGTGCTTCTT & 35 \\
\hline- & Competitor for DELTA $495 B$ & AGTTAGCCGGCGCTTCKT & 35 \\
\hline- & Competitor for DELTA495C & AATTAGCCGGTGCTTCTT & 35 \\
\hline HGC69A & $\begin{array}{l}\text { Actinobacteria } \\
\text { (high } G+C \text { gram positive bacteria) }\end{array}$ & TATAGTTACCACCGCCGT & 25 \\
\hline- & Competitor for HGC69A & TATAGTTACGGCCGCCGT & 25 \\
\hline $\mathrm{LGC} 34 \mathrm{~A}^{\mathrm{c}}$ & $\begin{array}{l}\text { Firmicutes } \\
\text { (low G+C gram positive bacteria) }\end{array}$ & TGGAAGATTCCCTACTGC & 35 \\
\hline $\mathrm{LGC} 34 \mathrm{~B}^{\mathrm{c}}$ & $\begin{array}{l}\text { Firmicutes } \\
\text { (low } G+C \text { gram positive bacteria) }\end{array}$ & CGGAAGATTCCCTACTGC & 35 \\
\hline LGC354C & $\begin{array}{l}\text { Firmicutes } \\
\text { (low G+C gram positive bacteria) }\end{array}$ & CCGAAGATTCCCTACTGC & 35 \\
\hline PS56a & Pseudomonas sp. & GCTGGCCTAGCCTTC & 20 \\
\hline PPu56a & Pseudomonas putida & GCTGGCCTAACCTTC & 20 \\
\hline
\end{tabular}


Fig.1 Schematic of experimental setup: a) BFs system b) BTF system
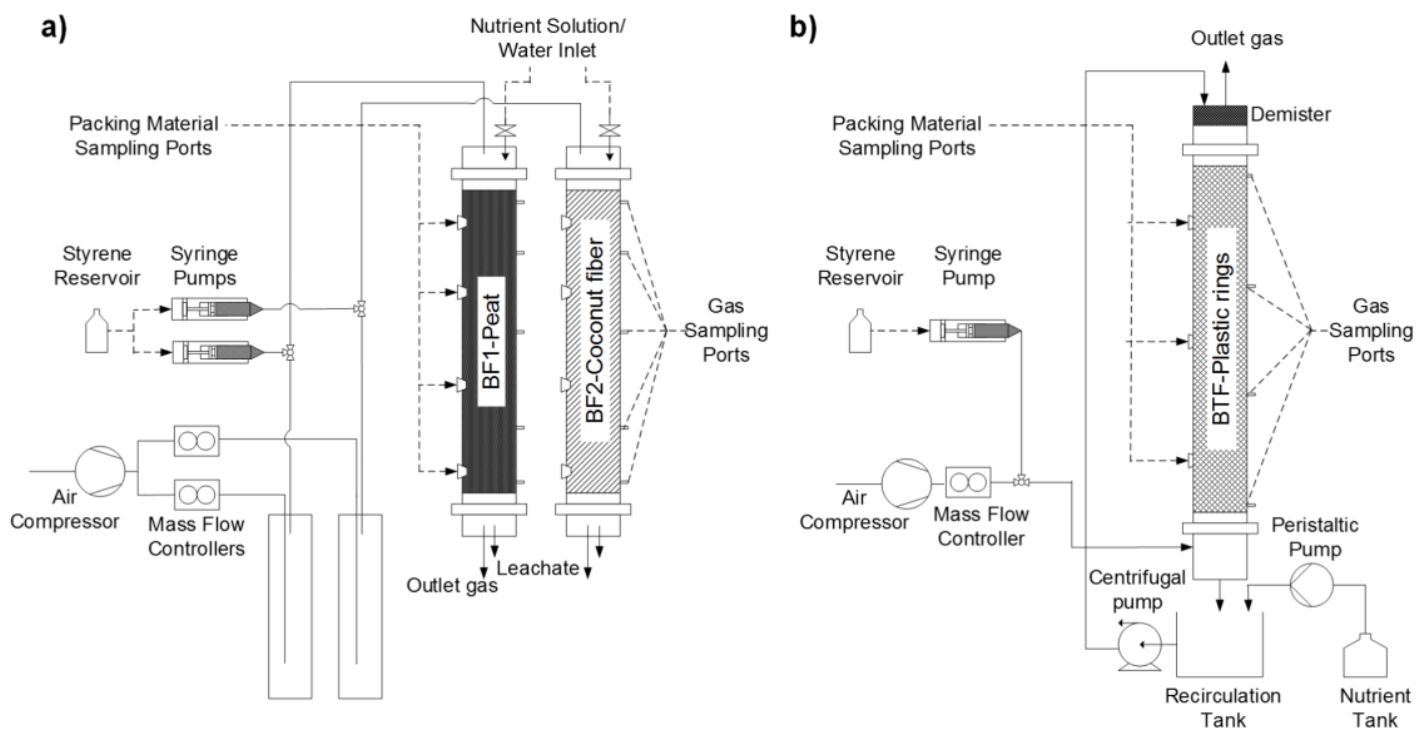
Fig.2 Evolution of the RE $(\diamond)$, inlet concentration $(\diamond)$ and outlet concentration $(\diamond)$ in the BFs: a) peat BF (BF1-P) and b) coconut fibre BF (BF2-C). Evolution of pressure drop $(\diamond)$ and moisture content in the top $(\diamond)$ and in the bottom $(\diamond)$ for the BFs: c) peat $\mathrm{BF}(\mathrm{BF} 1-\mathrm{P})$ and $\mathbf{d})$ coconut fibre $\mathrm{BF}(\mathrm{BF} 2-\mathrm{C})$
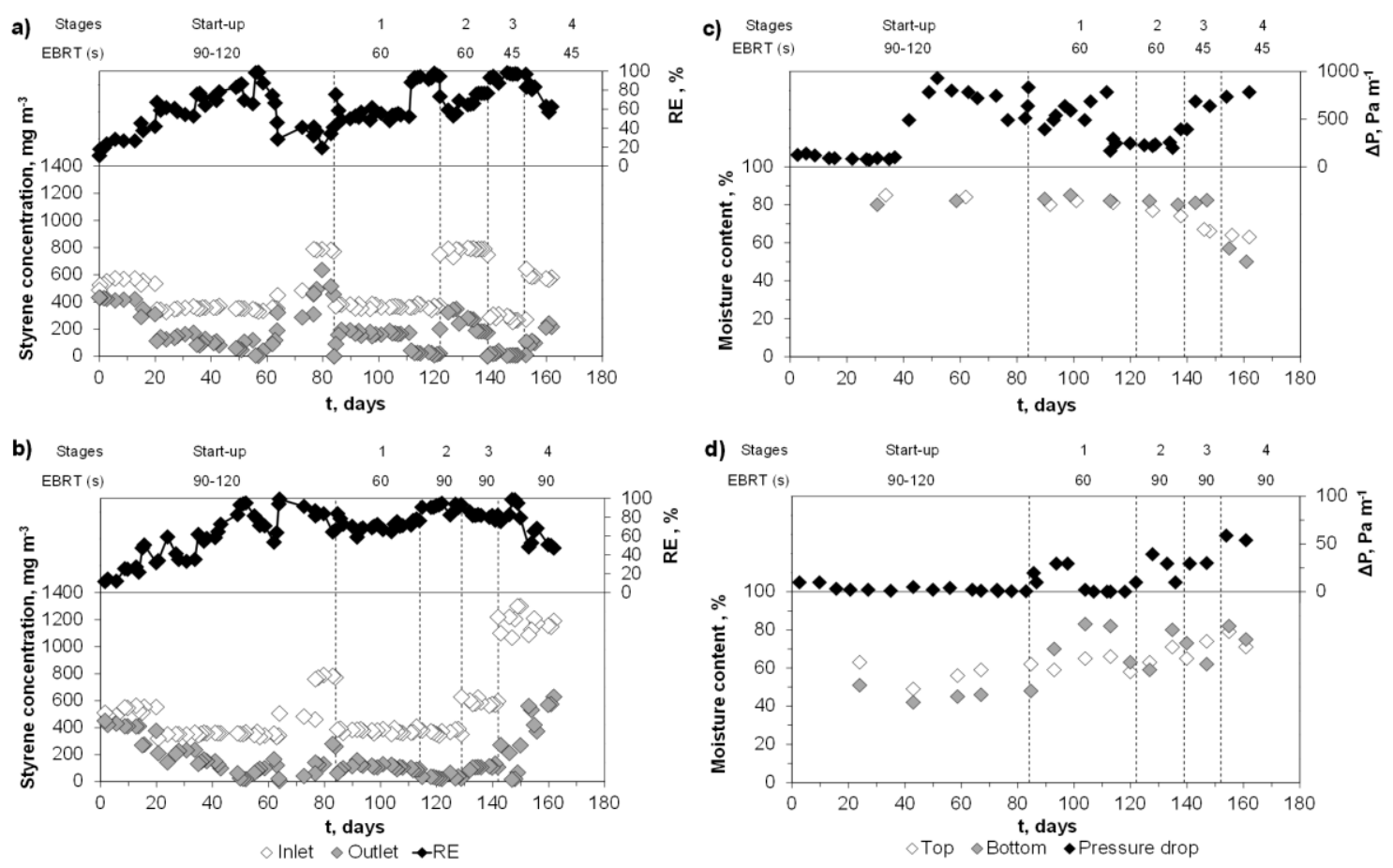
Fig.3 a) Evolution of the RE $(\diamond)$, inlet concentration $(\diamond)$ and outlet concentration $(\diamond)$ in the BTF. b) Evolution of pressure drop $(\diamond)$ and $\mathrm{pH}(\odot)$
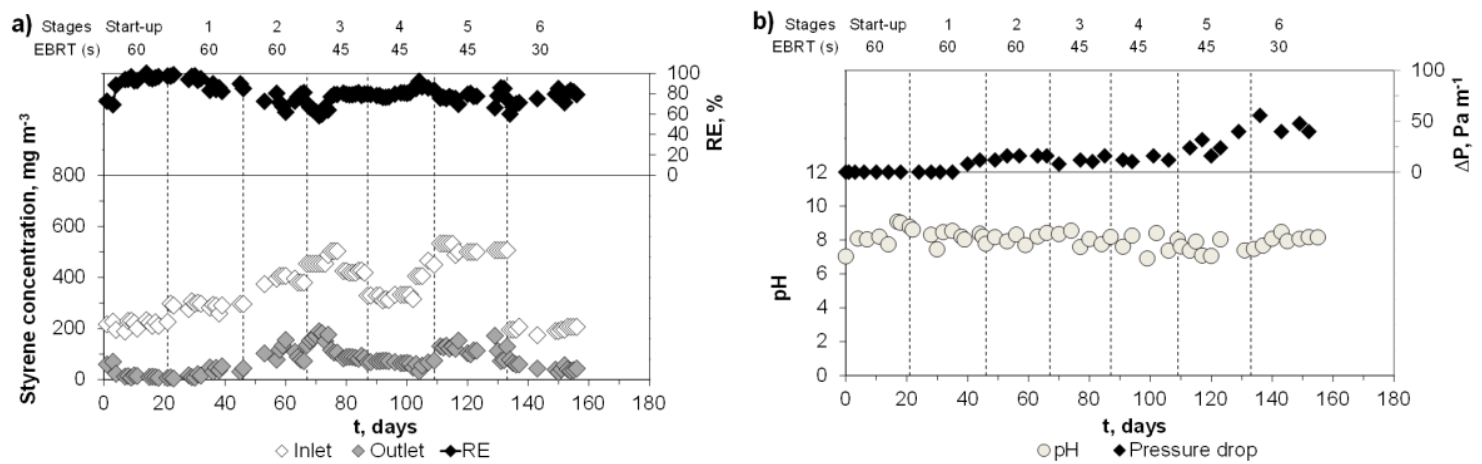
Fig.4 EC versus IL for different EBRT $30 \mathrm{~s}(\times), 45 \mathrm{~s}(\boldsymbol{\Delta}), 60 \mathrm{~s}(\diamond)$ and $90 \mathrm{~s}(\boldsymbol{O})$ : a) peat BF (BF1-P), b) coconut fibre BF (BF2-C) and c) BTF
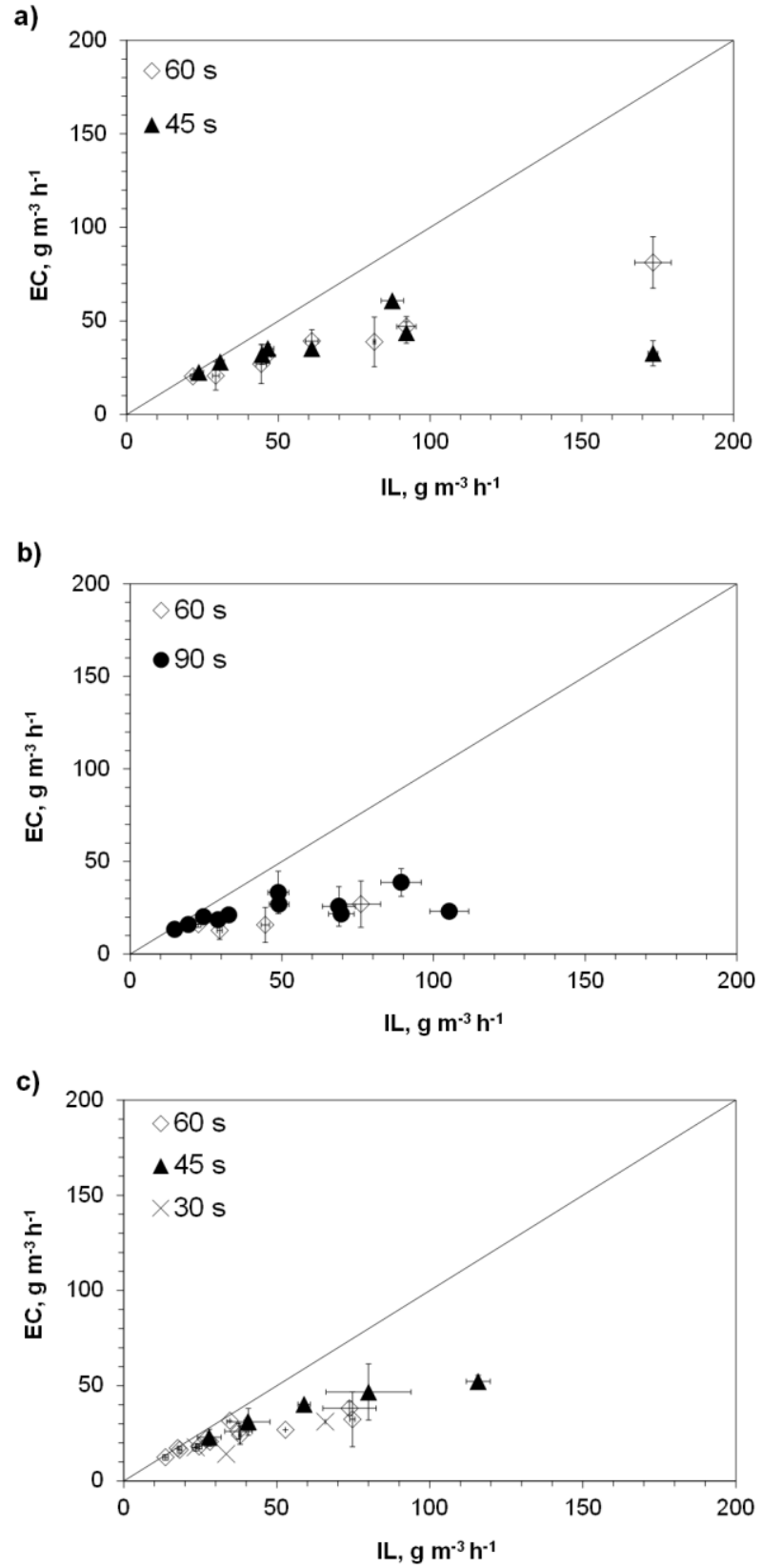
Fig.5 Production of carbon dioxide vs. EC obtained during experimental period: a) peat $\mathrm{BF}(\mathrm{BF} 1-\mathrm{P}), \mathbf{b})$ coconut fibre $\mathrm{BF}(\mathrm{BF} 2-\mathrm{C})$ and $\mathbf{c}) \mathrm{BTF}$
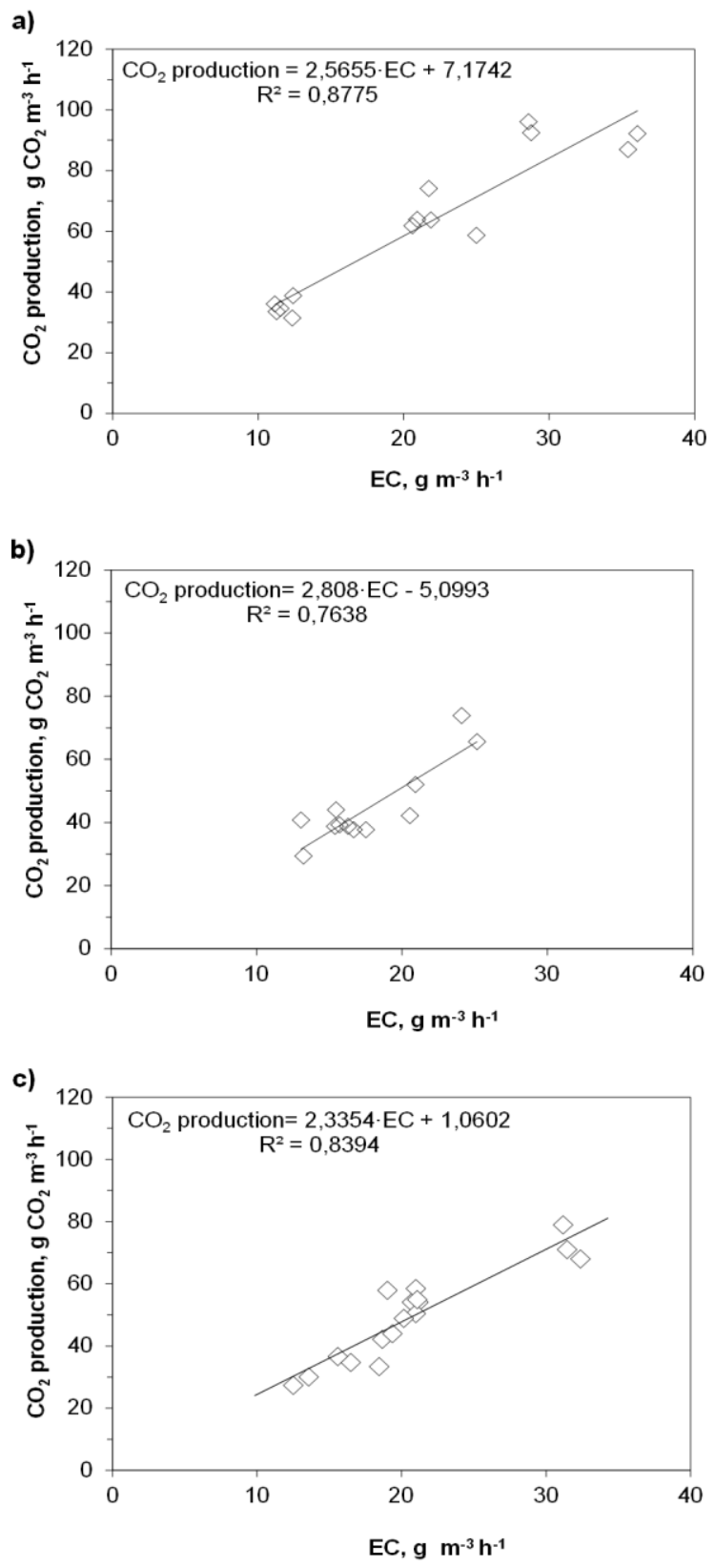
Fig.6 DGGE image of the Pseudomonas putida strain CECT 324, the enriched culture with Pseudomonas putida strain CECT 324 at day 0 (inoculum 1) and BFs samples on days 105,142 and 156 of experimental period

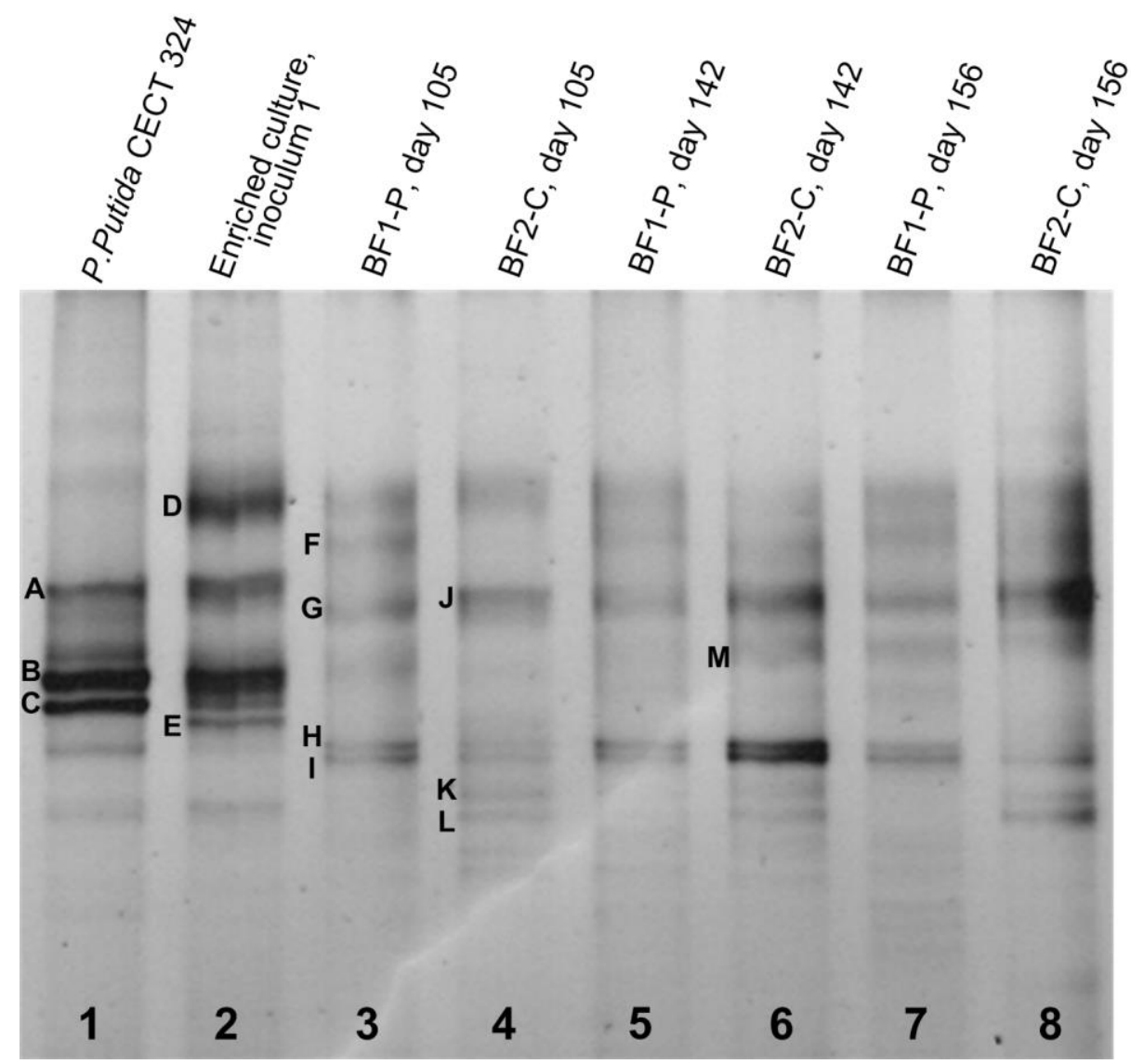


Fig.7 Time-dependent changes in bacterial community. Results corresponding to general FISH probes in: a) peat $\mathrm{BF}(\mathrm{BF} 1-\mathrm{P}), \mathbf{b})$ coconut fibre biofilter $(\mathrm{BF} 2-\mathrm{C})$ and c) BTF; and specific FISH probes in d) peat BF (BF1-P), e) coconut fibre biofilter (BF2C) and f) BTF. Bars represent the upper and lower bounds of the error of the technique.
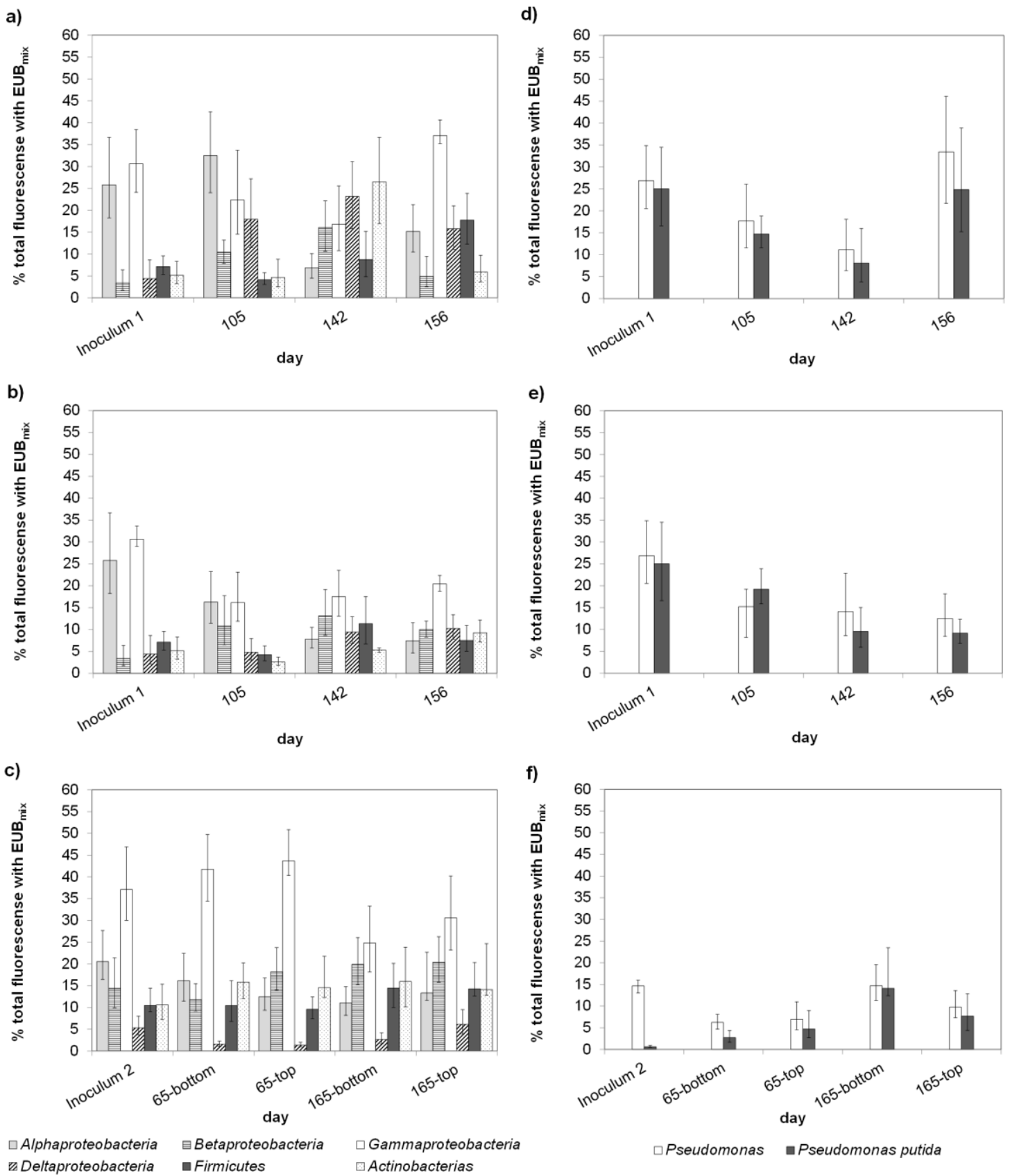